\title{
An Adaptation Method for Removing Arsenate Species from Water Solution
}

\author{
Sainyam Galhotra $^{1}$, Shigeru Kanemitsu ${ }^{2}$, Hiroyuki Kondo ${ }^{3}$ \\ ${ }^{1}$ Xerox Research Center India, Bangalore \\ ${ }^{2}$ Dept. of Information, Kinki University, Fukuoka, Japan \\ ${ }^{3}$ Faculty of Environ. Chemistry, Fukuoka Women's University, Fukuoka, Japan
}

Email address:

sainyam.galhotra@xerox.com (S. Galhotra),kanemitu@fuk.kindai.ac.jp (S. Kanemitsu), kondo1808@fwu.ac.jp (H. Kondo)

\section{To cite this article:}

Sainyam Galhotra, Shigeru Kanemitsu, Hiroyuki Kondo. An Adaptation Method for Removing Arsenate Species from Water Solution. Pure and Applied Mathematics Journal. Special Issue: Abridging over Troubled Water---Scientific Foundation of Engineering Subjects.

Vol. 4, No. 2-1, 2015, pp. 47-54. doi: 10.11648/j.pamj.s.2015040201.19

\begin{abstract}
This paper is based on the idea of adaptation under which we mean the replacement of one element in a system with another with similar aspects. The first adaptation comes from the replacement of orthophospheric acid $\mathrm{H}_{3} \mathrm{PO}_{4}$ by arsenious acid $\mathrm{H}_{3} \mathrm{AsO}_{4}$. There is a close relation between calcium-sulfate and calcium carbonate-arsenate species. The main objective of this note is to give an explicit formula for the ratio of each arsenal species to the total and to make an adaptation of the former by the latter to develop a new adsorption material of arsenic acid which spends almost no energy. Some recently proposed methods of using calcium sulphate or other material has ambivalent aspects regarding energy spending as well as the treatment after adsorption.
\end{abstract}

Keywords: Arsenate, Adsorption, Acidity (pH), Water Treatment

\section{Introduction}

The problem we are facing in the 21 st century is decidedly that of getting as much as energy without giving too much burden on the environment. This problem, however, has been unnoticed, or noticed but neglected, by rapidly developing countries which want to attain swift industrial success. This is the track that we have once gone along and we know what will come. Thus, energy and environmental protection are the two sides of a coin and cannot be separated.

In this paper, as a manifestation of the principle of environmental protection with little energy, we shall consider the adsorption of arsenious acid by calcium carbonate.

Arsenic compounds contained in underground water are highly poisonous and when used as drinking water, it leads to possible damaging of health including blackfoot disease. There are many significant health damages reported in Bangladesh and India, especially in West Bengal area, as well as the wide area underground water pollution by arsenic compounds in southern area of Fukuoka Prefecture, Japan, revealed in 1994, most of which are due to natural causes.

The ionic characteristics of arsenic compounds is associated to that of the sodium carbonate and calcium carbonate and higher concentration of arsenic compounds can be seen in deep sodium carbonate type underground water.

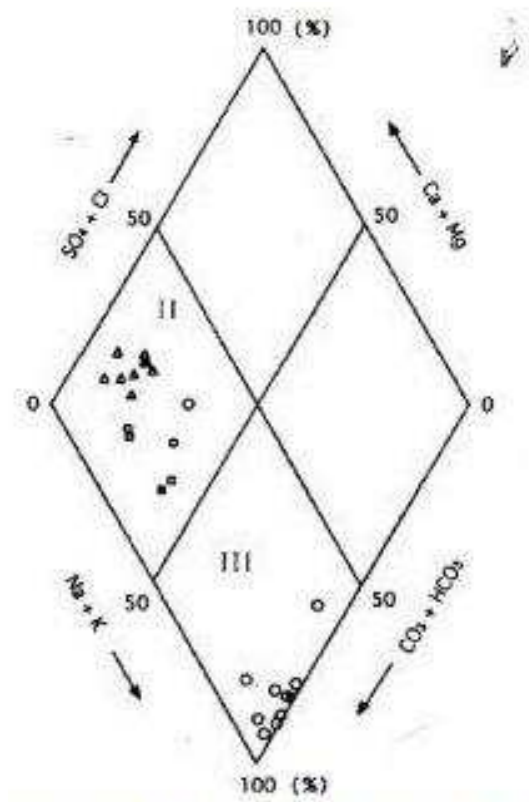

Fig. 1. Key Diagram of As contained in ground waters $(n=25)$ 
In Fig. I, region II shows Calcium carbonate type $(\mathrm{n}=14$, As average $0.023 \mathrm{mg} / \ell$ ) while Region III shows sodium carbonate type $(\mathrm{n}=14$, As average $0.075 \mathrm{mg} / \ell$ ).

There is a long history of inhibition, by calcium adsorption, of eutrophication of waters, resulting from too much phosphate whose main ingredient is orthophospheric acid $\mathrm{H}_{3} \mathrm{PO}_{4}$. The third author in his thesis [6] took up the problem of removal of arsenious acid $\mathrm{H}_{3} \mathrm{AsO}_{4}$ by calcium adsorption. Our study as well as his is based on the principle of adaptation to the effect that chemical elements of similar structures and nature may be exchanged, yielding similar results and analysis can be done in much the same way.

In his thesis, he made a series of extensive experiments on calcium adsorption of arsenic acid on the adaption principle, i.e. substituting arsenic acid for orthophospheric acid. There were several candidates for adsorption material including coral lime stone, activated alumina and calcium carbonate. $\mathrm{He}$ used three types of granules of oyster shells all of size smaller than $1 \mathrm{~mm}$ : Type I are natural oyster shells, Type II and III are those which are calcined at $600^{\circ} \mathrm{C}$ for 2 hours with Type II in pelleted. Experiments were made with As water solution of 20 $\mathrm{ml}$ with As concentration $50 \mu \mathrm{g} / \mathrm{ml}$. By his thorough investigation, it has been revealed that calcined oyster shells II, III showed 84.6 percent rate of adsorption, almost equal to that of activated alumina. This rate improved for higher concentration of As at concentration 10 2000 g/ml. Type I shells showed 17 37 percent adsorption rate for the use of more than $0.5 \mathrm{~g}$ and $2 \mathrm{~g}$ the rate was the highest.

The $\mathrm{pH}$ value of the resulting water solution was $8.1 \sim 9.0$ for Type I while it was 9.8 10.7 for Type II and III, surpassing the tap water limit of 5.8 8.6. The third author conjectured that the reason for better adsorption due to the fact that by calcination, calcium carbonate changes into water-soluble calcium oxide $\mathrm{CaO}$ (quicklime). He confirmed his conjecture by using the neutralized Type II shells which showed weaker adsorption efficiency. It has been verified that Type II, III shells are very effective in adsorption but have the defect of producing strong alkali solution.

Recently there appeared a paper [10] which proposes the use of calcium sulfate (gypsum) $\mathrm{CaSO}_{4}$ as adsorption material for arsenious acid. This lies at the opposite end of the spectrum of adsorption, yielding strong acidity in addition to sulphur although it has a far stronger in adsorbing power than calcium carbonate.

The same problem occurs with oyster shells which liquate out heavy metal ions contained in them, including $\mathrm{Cr}$, Sr, Mo from calcined ones and $\mathrm{Sr}, \mathrm{Mo}, \mathrm{Mn}$ from Type I, causing a plausible secondary pollution.

Calcined calcium carbonate (quicklime), as adsorption material, suffers from two defects, i.e. it is strong alkali and needs to be burnt at the temperature of $900^{\circ} \sim 1500^{\circ}$. Shell lime is made by calcination at $300^{\circ}$ while the building material is made at $1500^{\circ}$, which gives rise to mortar.

It seems that adsorption of As and liquation of ingredients are in ambivalent balance and we should choose the most economical Type I shells since they are industrial wastes.

Thus Type I shells may be worth further being studied as to why they show the most effective rate for $2 \mathrm{~g}$ for water solution $20 \mathrm{ml}$ of As concentration $50 \mu \mathrm{g} / \mathrm{ml}$ and why the rate decreases thereafter. The third author conjectures that this might be caused by the rising of $\mathrm{pH}$ of the solution.

There are subtleties of dissociation of which family of acids are prevailing according to the proton index. We restrict to the range 5.8 8.6 which is allowed as tap water in Japan. Our purpose is to make clear the underlying chemical structure by mathematical reasoning.

This paper is a starter for extensive research on the adaptation principle. The optimal choice of the adsorption material according to higher concentration of As or its equivalent is conducted elsewhere.

\section{Adaption Principle}

Let $\mathrm{X}$ denote one of $\mathrm{SO}_{4}^{2}, \mathrm{HCO}_{3}, \mathrm{CO}_{3}{ }_{3}$ and $\mathrm{F}_{2}{ }_{2}$. Their compound with calcium ion $\mathrm{CaSO}_{4}, \mathrm{Ca}\left(\mathrm{HCO}_{3}\right)_{2}, \mathrm{CaCO}_{3}$ and $\mathrm{CaF}_{2}$ are calcium sulfate, calcium hydro-carbonate, calcium carbonate, calcium fluoride, respectively, referred to above. The well-known formula for the solubility product reads

$$
K_{s, \mathrm{CaX}}=\left[\mathrm{Ca}^{2+}\right]\left[X^{2-}\right]
$$

and for $X=\mathrm{SO}_{4}$, Eq. (1) reads

$$
K_{s, \mathrm{CaSO}_{4}}=\left[\mathrm{Ca}^{2+}\right]\left[\mathrm{SO}_{4}{ }^{2-}\right]=2.4 \times 10^{-5} \mathrm{~mol}^{2} \mathrm{dm}^{-6},
$$

for $\mathrm{HCO}_{3}^{-}$

$$
K_{s, \mathrm{CaH}\left(\mathrm{CO}_{3}\right)^{2}}=\left[\mathrm{Ca}^{2+}\right] \%\left[\mathrm{HCO}_{3}^{-}\right]^{2}=1.02 \mathrm{~mol}^{3} \mathrm{dm}^{-9}
$$

and for $X=\mathrm{CO}_{3}^{2-}$

$$
K_{s, \mathrm{CaCO}_{3}}=\left[\mathrm{Ca}^{2+}\right]\left[\mathrm{CO}_{3}^{2-}\right]=4.8 \times 10^{-9} \mathrm{~mol}^{2} \mathrm{dm}^{-6} .
$$

We notice the principle to the effect that the smaller the exponent a of $10^{\mathrm{a}}$ is, the less soluble the material is, i.e. the more precipitative. In the above case, $\mathrm{CaSO}_{4}$ is more soluble than $\mathrm{CaCO}_{3}$.

On the other hand, the solubility product formula for the calcium arsenate $\mathrm{Ca}_{3}\left(\mathrm{AsO}_{4}\right)_{2}$ is

$$
K_{s, \mathrm{Ca}_{3}\left(\mathrm{AsO}_{4}\right)_{2}}=\left[\mathrm{Ca}^{2+}\right]^{3}\left[\mathrm{AsO}_{4}{ }^{3-}\right]^{2}=6.8 \times 10^{-19} \mathrm{~mol}^{5} \mathrm{dm}^{-15} .
$$

By the above principle, calcium arsenate is much less soluble than calcium sulfate and calcium carbonate, i.e. in the presence of the latter, the arsenate ions $\mathrm{AsO}_{4}{ }^{3}$ precipitate, thereby adsorption being done. They arise by the dissociation of the protons from arsenic acid in the following successive dissociation equilibrium.

$$
\mathrm{H}_{3} \mathrm{AsO}_{4} \leftrightarrow \mathrm{H}^{+}+\mathrm{H}_{2} \mathrm{AsO}_{4}^{-}, K_{1}:=\left[\mathrm{H}^{+}\right]\left[\mathrm{H}_{2} \mathrm{AsO}_{4}^{-}\right] /\left[\mathrm{H}_{3} \mathrm{AsO}_{4}\right]=10^{-2.22} \mathrm{~mol} \mathrm{dm}^{-3},
$$




$$
\mathrm{H}_{2} \mathrm{AsO}_{4}{ }^{-} \leftrightarrow \mathrm{H}^{+}+\mathrm{HAsO}_{4}{ }^{2-}, K_{2}:=\left[\mathrm{H}^{+}\right]\left[\mathrm{HAsO}_{4}{ }^{2-}\right] /\left[\mathrm{H}_{2} \mathrm{AsO}_{4}{ }^{-}\right]=10^{-6.98} \mathrm{~mol} \mathrm{dm}^{-3}
$$

and

$$
\mathrm{HAsO}_{4}{ }^{2-} \leftrightarrow \mathrm{H}^{+}+\mathrm{AsO}_{4}{ }^{3-}, K_{3}:=\left[\mathrm{H}^{+}\right]\left[\mathrm{AsO}_{4}{ }^{3-}\right] /\left[\mathrm{HAsO}_{4}{ }^{2-}\right]=10^{-11.4} \mathrm{~mol} \mathrm{dm}{ }^{-3}
$$

Let $\mathrm{A}_{\mathrm{S}_{\mathrm{T}}}$ denote the total concentration of all arsenic species:

$$
\mathrm{As}_{T}=\left[\mathrm{H}_{3} \mathrm{AsO}_{4}\right]+\left[\mathrm{H}_{2} \mathrm{AsO}_{4}{ }^{-}\right]+\left[\mathrm{HAsO}_{4}{ }^{2-}\right]+\left[\mathrm{AsO}_{4}{ }^{3-}\right]
$$

and let $\alpha_{j}$ denote the ratio of each arsenic species against the total:

$$
\alpha_{j}=\left[\mathrm{H}_{3-j} \mathrm{AsO}_{4}{ }^{j-}\right] / \mathrm{As}_{T}, \quad 0 \leq j \leq 3,
$$

$$
\alpha_{3}=\left[\mathrm{AsO}_{4}^{3-}\right] / \mathrm{As}_{T}
$$

where $\alpha_{0}=\left[\mathrm{H}_{3} \mathrm{AsO}_{4}\right] / A S_{T}$ and

$$
K_{j}=\left[\mathrm{H}^{+}\right]\left[\mathrm{H}_{3-j} \mathrm{AsO}_{4}{ }^{j-}\right] /\left[\mathrm{H}_{4-j} \mathrm{AsO}_{4}{ }^{(j-1)-}\right]=\left[\mathrm{H}^{+}\right] \frac{\left[\mathrm{H}_{3-j} \mathrm{AsO}_{4}{ }^{j-}\right] / \mathrm{As}_{T}}{\left[\mathrm{H}_{4-j} \mathrm{AsO}_{4}{ }^{\left({ }^{-1)-}\right)}\right] / \mathrm{As}_{T}}=\left[\mathrm{H}^{+}\right] \frac{\alpha_{j}}{\alpha_{j-1}}, 1 \leq j \leq 3,
$$

we obtain by Eq. 12

$$
\alpha_{j}=K_{j}\left[\mathrm{H}^{+}\right]^{-1} \alpha_{j-1}, 1 \leq j \leq 3,
$$

the relation between successive terms of the sequence, whence inductively we conclude that

$$
\alpha_{j}=K_{j} \cdots K_{1}\left[\mathrm{H}^{+}\right]^{-j} \alpha_{0}, \quad 1 \leq j \leq 3 .
$$

Recall that the sum of $\alpha_{j}{ }^{\prime} s$ is 1 by Eq. 10

$$
\sum_{j=1}^{3} \alpha_{j}=1
$$

Substituting from Eq. 14 we conclude that

$$
\alpha_{0}=\frac{1}{1+\sum_{i=1}^{3} K_{i} \cdots K_{1}\left[\mathrm{H}^{+}\right]^{-i}}
$$

Hence from Eq. 14 and Eq. 16 we obtain

Theorem 1: We have the explicit formula

$$
\alpha_{j}=\alpha_{j}\left(\left[\mathrm{H}^{+}\right]\right)=\frac{K_{j} \cdots K_{1}\left[\mathrm{H}^{+}\right]^{-j}}{1+\sum_{i=1}^{3} K_{i} \cdots K_{1}\left[\mathrm{H}^{+}\right]^{-i}}, \quad 1 \leq j \leq 3
$$

Or more concretely,

$\alpha_{j}=\alpha_{j}\left(\left[\mathrm{H}^{+}\right]\right)=\frac{K_{j} \cdots K_{1}\left[\mathrm{H}^{+}\right]^{3-j}}{\left[\mathrm{H}^{+}\right]^{3}+10^{-2.22}\left[\mathrm{H}^{+}\right]^{2}+10^{-9.2}\left[\mathrm{H}^{+}\right]+10^{-20.6}}$.

Proof. Eq. 18 follows from the numerical values in Eq. 6, Eq. 7 , Eq. 8

$$
K_{1} K_{2}=10^{-9.2}, K_{1} K_{2} K_{3}=10^{-20.6}
$$

and by multiplying by $\left(\left[H^{+}\right]\right)^{3}$ the numerator and the denominator of Eq. 17.

$$
\text { E.g. } \alpha_{2}=\alpha_{2}\left(\left[\mathrm{H}^{+}\right]\right)=\frac{10^{-9.2}\left[\mathrm{H}^{+}\right]}{\left[\mathrm{H}^{+}\right]^{3}+10^{-2.22}\left[\mathrm{H}^{+}\right]^{2}+10^{-9.2}\left[\mathrm{H}^{+}\right]+10^{-20.6}}
$$

and

$$
\alpha_{3}=\alpha_{3}\left(\left[\mathrm{H}^{+}\right]\right)=\frac{10^{-20.6}}{\left[\mathrm{H}^{+}\right]^{3}+10^{-2.22}\left[\mathrm{H}^{+}\right]^{2}+10^{-9.2}\left[\mathrm{H}^{+}\right]+10^{-20.6}} .
$$

Eliminating $\left[\mathrm{Ca}^{2+}\right]$ from Eq. 1 and Eq. 5 , we obtain

$$
\frac{K_{s, \mathrm{CaX}}{ }^{3}}{K_{s, \mathrm{Ca}_{3}\left(\mathrm{AsO}_{4}\right)_{2}}}=\frac{\left[X^{2-}\right]^{3}}{\left[\mathrm{AsO}_{4}^{3-}\right]^{2}} .
$$

From Eq. 11 we have

$$
\left[\mathrm{AsO}_{4}{ }^{3-}\right]=\alpha_{3} \mathrm{As}_{T},
$$

whence we deduce from Eq. 21 that

$$
\left[X^{2-}\right]=R\left(\alpha_{3} \mathrm{As}_{T}\right)^{2 / 3}
$$

on writing

$$
R=R_{X}=\frac{K_{s, \mathrm{CaX}}}{\left(K_{s, \mathrm{Ca}_{3}\left(\mathrm{AsO}_{4}\right)_{2}}\right)^{\frac{1}{3}} .}
$$

In the case of $\mathrm{X}=\mathrm{HCO}_{3}^{-}$,

$$
R_{\mathrm{HCO}}=\frac{1.06 \mathrm{~mol}_{3}^{3} \mathrm{dm}^{-9}}{\left(6.8 \times 10^{-19} \mathrm{~mol}^{5} \mathrm{dm}^{-15}\right)^{\frac{1}{3}}}=0.546 \times 10^{-2} \mathrm{~mol}^{\frac{1}{3}} \mathrm{dm}^{-1} \text {. }
$$

\section{From}




$$
\mathrm{Ca}_{3}\left(\mathrm{AsO}_{4}\right)_{2} \leftrightarrow 3 \mathrm{Ca}^{2+}+2 \mathrm{AsO}_{4}{ }^{3-},
$$

we find that the concentration of $\mathrm{As}_{\mathrm{T}}$ is approximately $3 / 2$ of that of $\mathrm{Ca}_{3}$, whence we deduce the formula

$$
\left[\mathrm{Ca}^{2+}\right]=\left[X^{2-}\right]+\frac{3}{2} \mathrm{As}_{T}
$$

as in $[10,11]$. Then substituting Eq. 22 we obtain

$$
\left[\mathrm{Ca}^{2+}\right]=R_{X}\left(\alpha_{3} \mathrm{As}_{T}\right)^{2 / 3}+\frac{3}{2} \mathrm{As}_{T} .
$$

Substituting Eq. 22 and Eq. 27 in Eq. 1, we deduce that

$$
K_{s, \mathrm{CaX}}=R_{X}^{2} \alpha_{3}^{4 / 3} \mathrm{As}_{T}^{4 / 3}+\frac{3}{2} R_{X} \alpha_{3}^{2 / 3} \mathrm{As}_{T}^{5 / 3}
$$

and we are to solve the quintic equation with coefficients containing the parameter $\left[\mathrm{H}^{+}\right]$

$$
\frac{3}{2} R_{X} \alpha_{3}^{2 / 3} P^{5}+R_{X}^{2} \alpha_{3}^{4 / 3} P^{4}-K_{s, \mathrm{CaX}}=0
$$

on writing $\mathrm{P}=\mathrm{As}_{\mathrm{T}}{ }^{1 / 3}$. E.g. by the well-known Newton iterative method, the equation Eq. 29 may be solved numerically. We are to solve it with $\mathrm{X}=\mathrm{HCO}_{3}{ }^{-}$i.e. with the value in Eq. 24.

$$
P^{5}+\frac{2}{3} R_{\mathrm{CO}_{3}} \alpha_{3}{ }^{2 / 3} P^{4}-\frac{2}{3} R_{\mathrm{CO}_{3}}{ }^{-1} \alpha_{3}{ }^{-2 / 3} K_{s, \mathrm{CaCO}_{3}}=0 \text { (30) }
$$

with $\alpha_{3}=\alpha_{3}\left(\left[H^{+}\right]\right)=$defined by Eq. 20, Fig. 2 shows the graph of $\mathrm{P}=\mathrm{As}_{\mathrm{T}}{ }^{1 / 3}$.

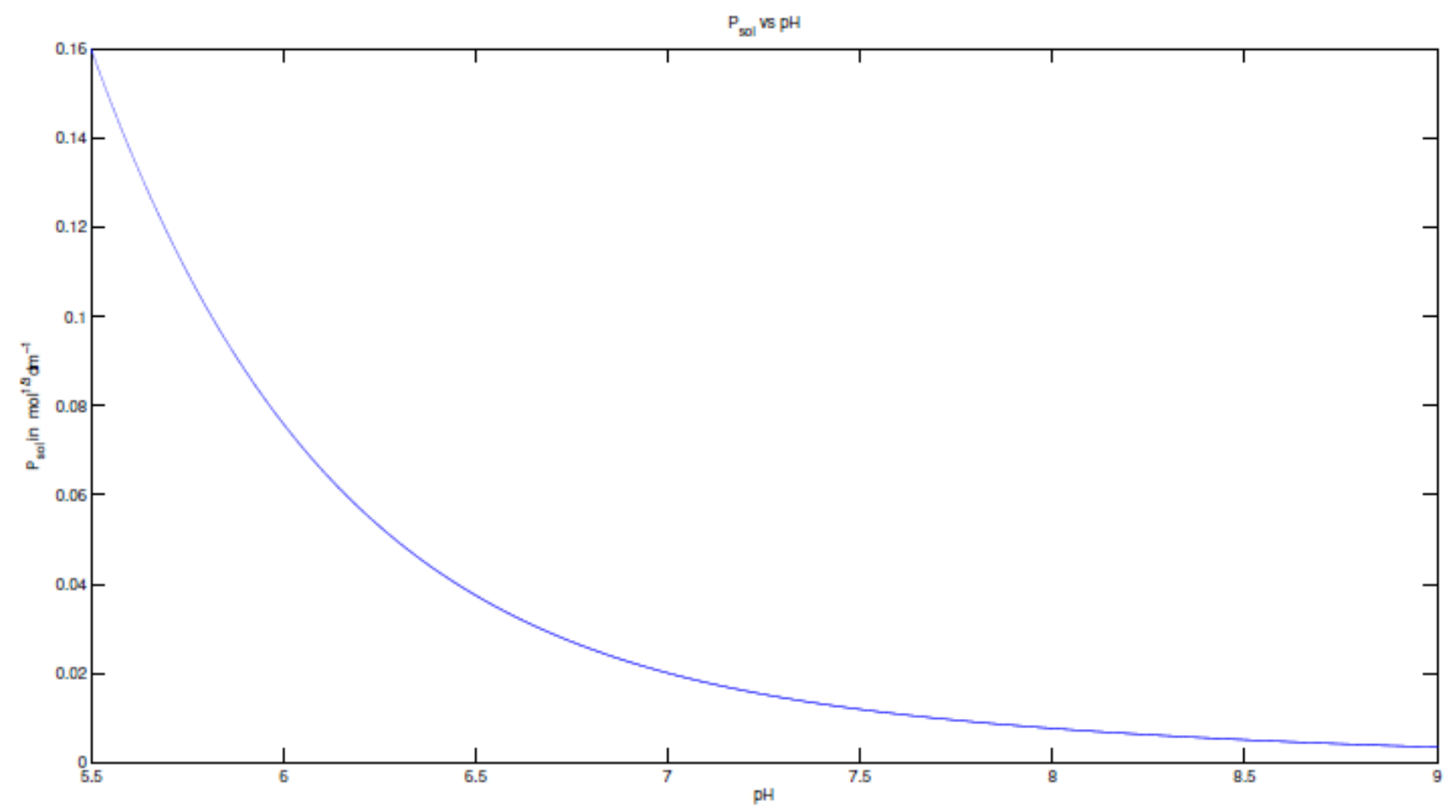

Fig. 2. The positive solution of the quantic equation for different values of $p H$ between 5.5 and 8.5

Remark: The acidity of tap water is restricted to the range 5.8 8.6 by law and underground water has neutral or weak alkali and so the $\mathrm{pH}$ lies near and greater than 7. In [10] the $\mathrm{pH}$ range is restricted to $7 \sim 10$ since $\mathrm{K}_{2} \approx 10^{-7}, \alpha_{2}=10^{-7}\left[\mathrm{H}^{+}\right]^{-1} \alpha_{1}$ and for $\mathrm{pH}=7$, we have $\alpha_{2}=\alpha_{1}$ and as $\mathrm{pH}$ increases the proportion of $\mathrm{H}_{2} \mathrm{AsO}_{4}{ }^{-}$against $\mathrm{HAsO}_{4}{ }^{2-}$ steadily decreases. In [10] the argument goes in the following lines. $\mathrm{HAsO}_{4}{ }^{2-}$ starts predominating $\mathrm{H}_{2} \mathrm{AsO}_{4}{ }^{1-}$, so that one may approximate the amount of $\mathrm{HasO}_{4}{ }^{2-}$ and so one may obtain the amount of $\mathrm{As}_{\mathrm{T}}$ by solving the Eq. 28 with $\mathrm{X}=\mathrm{SO}_{4}^{-}$.

In the case of $\mathrm{HCO}_{3}{ }^{-}$, it predominates $\mathrm{CO}_{3}{ }^{2-}$ at $\mathrm{pH}=8.3$ by 100 times and only at $\mathrm{pH}=10.3$, their amount becomes equal. Hence there are three ways to go. We assume the $\mathrm{pH}$ range to $5.8 \sim 8.3$, which is more practical or we assume $\mathrm{pH}>10.3$ Or we calcite the lime stone to produce quicklime. We can make a table of temperature needed for the degree of adsorption. 


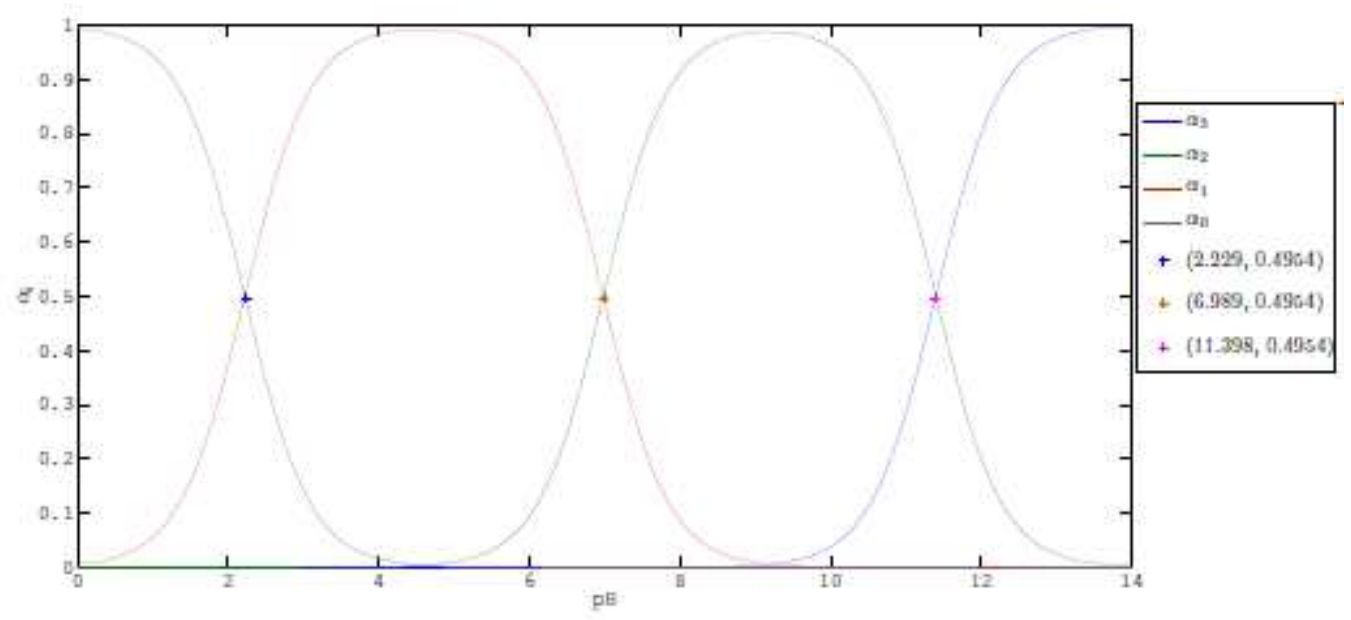

Fig. 3. $\alpha_{0,1,2,3}$ value for different values of $p H$

\section{Calcium Phosphate}

The solubility product formula Eq. 1 takes on another form according to the compound we consider. For the ease of detection, in progressive experiments, we have been trying to measure the amount of phosphate rather than arsenal, which should give as good detection result for the latter as the former, in view of the adaption principle referred to in Introduction. In this section we shall state the theoretical values for the ratios as in II.

Theorem 2: Let

$$
\beta_{j}=\frac{\left[\mathrm{H}_{3-j} \mathrm{PO}_{4}^{-j}\right]}{\mathrm{P}_{T}}
$$

Then Eq. 18 reads

$$
\beta_{j}=\beta_{j}\left(\left[\mathrm{H}^{+}\right]\right)=\frac{K_{j} \cdots K_{1}\left[\mathrm{H}^{+}\right]^{3-j}}{\left[\mathrm{H}^{+}\right]^{3}+7.5 \times 10^{-3}\left[\mathrm{H}^{+}\right]^{2}+4.65 \times 10^{-10}\left[\mathrm{H}^{+}\right]+9.95 \times 10^{-23}} .
$$

I.e.

$$
\begin{aligned}
& \beta_{1}=\beta_{1}\left(\left[\mathrm{H}^{+}\right]\right)=\frac{7.5 \times 10^{-3}\left[\mathrm{H}^{+}\right]^{2}}{\left[\mathrm{H}^{+}\right]^{3}+7.5 \times 10^{-3}\left[\mathrm{H}^{+}\right]^{2}+4.65 \times 10^{-10}\left[\mathrm{H}^{+}\right]+9.95 \times 10^{-23}}, \\
& \beta_{2}=\beta_{2}\left(\left[\mathrm{H}^{+}\right]\right)=\frac{4.65 \times 10^{-10}\left[\mathrm{H}^{+}\right]}{\left[\mathrm{H}^{+}\right]^{3}+7.5 \times 10^{-3}\left[\mathrm{H}^{+}\right]^{2}+4.65 \times 10^{-10}\left[\mathrm{H}^{+}\right]+9.95 \times 10^{-23}},
\end{aligned}
$$

and

$$
\beta_{3}=\beta_{3}\left(\left[\mathrm{H}^{+}\right]\right)=\frac{9.95 \times 10^{-23}}{\left[\mathrm{H}^{+}\right]^{3}+7.5 \times 10^{-3}\left[\mathrm{H}^{+}\right]^{2}+4.65 \times 10^{-10}\left[\mathrm{H}^{+}\right]+9.95 \times 10^{-23}} .
$$

Proof: Corresponding to Eq. 25, we have

$$
\mathrm{Ca}_{3}\left(\mathrm{PO}_{4}\right)_{2} \leftrightarrow 3 \mathrm{Ca}^{2+}+2 \mathrm{PO}_{4}{ }^{3-}
$$

so that Eq. 1 reads

$$
K_{s, \mathrm{Ca}\left((\mathrm{PO})_{4}\right)_{2}}=\left[\mathrm{Ca}^{2+}\right]^{3}\left[\mathrm{PO}_{4}^{3-}\right]^{2}=2.0 \times 10^{-29} \mathrm{~mol}^{5} \mathrm{dm}^{-15} .
$$

Eq. 7, 8, 9 read respectively

$$
\mathrm{H}_{3} \mathrm{PO}_{4} \leftrightarrow \mathrm{H}^{+}+\mathrm{H}_{2} \mathrm{PO}_{4}^{-}, \quad K_{1}:=\left[\mathrm{H}^{+}\right]\left[\mathrm{H}_{2} \mathrm{PO}_{4}^{-}\right] /\left[\mathrm{H}_{3} \mathrm{PO}_{4}\right]=7.5 \times 10^{-3} \mathrm{~mol} \mathrm{dm}^{-3},
$$




$$
\begin{aligned}
& \mathrm{H}_{2} \mathrm{PO}_{4}{ }^{-} \leftrightarrow \mathrm{H}^{+}+\mathrm{HPO}_{4}{ }^{2-}, \\
& K_{2}:=\left[\mathrm{H}^{+}\right]\left[\mathrm{HPO}_{4}{ }^{2-}\right] /\left[\mathrm{H}_{2} \mathrm{PO}_{4}{ }^{-}\right]=6.2 \times 10^{-8} \mathrm{~mol} \mathrm{dm}^{-3}
\end{aligned}
$$

and

$$
\begin{aligned}
& \mathrm{HPO}_{4}{ }^{2-} \leftrightarrow \mathrm{H}^{+}+\mathrm{PO}_{4}{ }^{3-} \\
& K_{3}:=\left[\mathrm{H}^{+}\right]\left[\mathrm{PO}_{4}{ }^{3-}\right] /\left[\mathrm{HPO}_{4}{ }^{2-}\right]=2.14 \times 10^{-13} \mathrm{~mol} \mathrm{dm}^{-3}
\end{aligned}
$$

Now Eq. 19 takes the form

$$
K_{1} K_{2}=4.65 \times 10^{-10}, \quad K_{1} K_{2} K_{3}=9.95 \times 10^{-23} .
$$

Incorporating these completes the proof.

Eq. 27 remains the same with As replaced by $\mathrm{PO}_{4}$ and we are to solve the quintic equation corresponding to Eq. 29

$$
\frac{3}{2} R_{X} \beta_{3}{ }^{2 / 3} P^{5}+R_{X}^{2} \beta_{3}^{4 / 3} P^{4}-K_{s, \mathrm{Ca} X}=0 .
$$

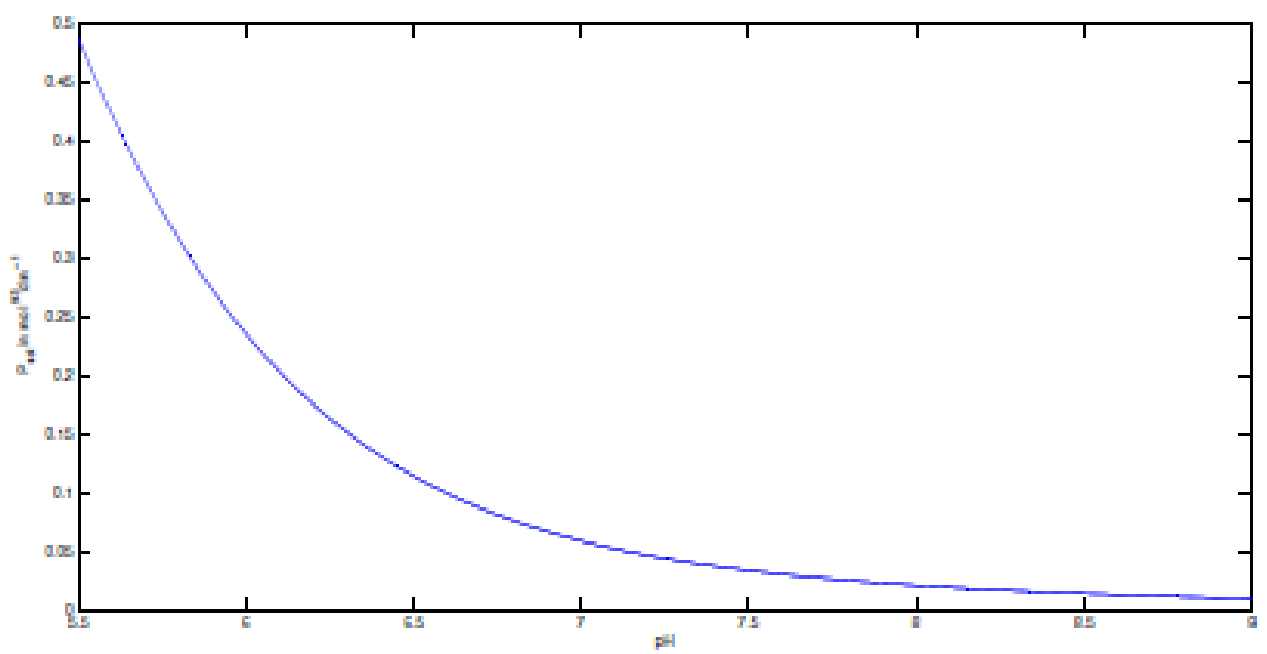

Fig. 4. The positive solution of the quantic equation for different values of $p H$ between 5.5 and 9

Fig. 3 shows the graph of $P=\left(\left(\mathrm{PO}_{4}\right)_{T}\right)^{1 / 3}$

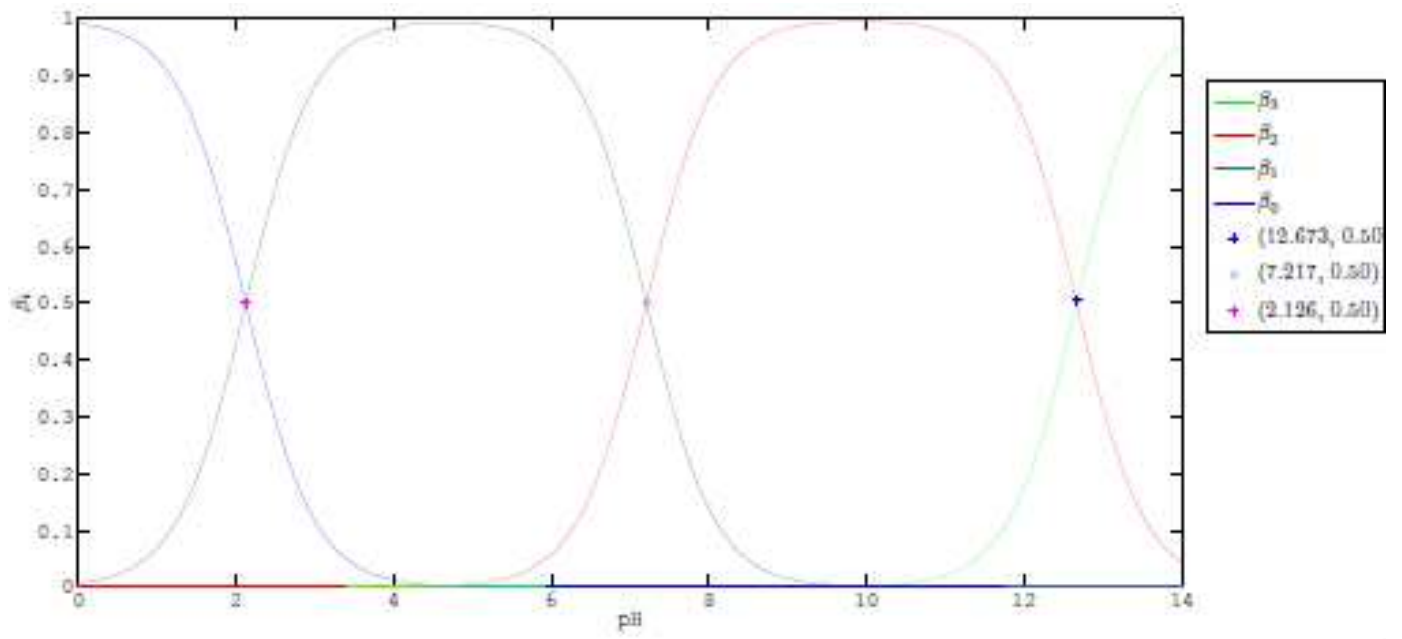

Fig. 5. $\beta_{0,1,2,3}$ value for different values of $\mathrm{pH}$ 


\section{Dissociation of Calcium Carbonate}

Since calcium carbonate is a weak acid, there is a subtle problem As to which ionic species prevails at a specified range of $\mathrm{pH}$. The following is a preliminary study on the dissociation equilibrium for calcium carbonate. First,

$$
\mathrm{CO}_{2}+\mathrm{H}_{2} \mathrm{O} \leftrightarrow \mathrm{H}_{2} \mathrm{CO}_{3}
$$

which indicates the solution of carbon dioxide with water and which is irrelevant to us here. What may have to do with are the following:

$$
\begin{gathered}
\mathrm{H}_{2} \mathrm{CO}_{3} \leftrightarrow \mathrm{H}^{+}+\mathrm{HCO}_{3}^{-}, \quad k_{2}=\left[\mathrm{H}^{+}\right]\left[\mathrm{HCO}_{3}^{-}\right] /\left[\mathrm{H}_{2} \mathrm{CO}_{3}\right]=10^{-6.3} \\
\mathrm{HCO}_{3}^{-} \leftrightarrow \mathrm{H}^{+}+\mathrm{CO}_{3}^{2-}, \quad k_{3}=\left[\mathrm{H}^{+}\right]\left[\mathrm{CO}_{3}^{-}\right] /\left[\mathrm{HCO}_{3}^{-}\right]=10^{-10.3}
\end{gathered}
$$

Along with eq. 10 we let

$$
\gamma_{j}=\left[\mathrm{H}_{2-j} \mathrm{CO}_{3}{ }^{j-}\right] / \mathrm{CO}_{T}, \quad 0 \leq j \leq 2,
$$

where $\mathrm{CO}_{\mathrm{T}}$ indicates the total amount of $\mathrm{CO}$. More concretely,

$$
\gamma_{0}=\left[\mathrm{H}_{2} \mathrm{CO}_{3}\right] / \mathrm{CO}_{T}, \gamma_{1}=\left[\mathrm{HCO}_{3}^{-}\right] / \mathrm{CO}_{T}, \gamma_{2}=\left[\mathrm{CO}_{3}^{2-}\right] / \mathrm{CO}_{T} .
$$

As with Theorem 1, we obtain

Theorem 3:

$$
\gamma_{1}=\frac{10^{-6.3}\left[\mathrm{H}^{+}\right]^{-1}}{1+10^{-6.3}\left[\mathrm{H}^{+}\right]^{-1}+10^{-16.6}\left[\mathrm{H}^{+}\right]^{-2}}, \gamma_{2}=\frac{10^{-16.6}\left[\mathrm{H}^{+}\right]^{-2}}{1+10^{-6.3}\left[\mathrm{H}^{+}\right]^{-1}+10^{-16.6}\left[\mathrm{H}^{+}\right]^{-2}} .
$$

Proof: In analogy to Eq. 12 we sum up to get

$$
k_{j+1}=\left[\mathrm{H}^{+}\right] \frac{\gamma_{j}}{\gamma_{j-1}}, \quad 1 \leq j \leq 2 .
$$

Hence we obtain the relation between the consecutive terms

$$
\gamma_{j}=k_{j+1}\left[\mathrm{H}^{+}\right]^{-1} \gamma_{j-1}, \quad 1 \leq j \leq 2 .
$$

whence inductively,

$$
\begin{gathered}
\gamma_{j}=k_{j+1} \cdots k_{2}\left[\mathrm{H}^{+}\right]^{-j} \gamma_{0}, \quad 1 \leq j \leq 2, \\
\gamma_{1}=k_{2}\left[\mathrm{H}^{+}\right]^{-1} \gamma_{0}, \quad \gamma_{2}=k_{3} k_{2}\left[\mathrm{H}^{+}\right]^{-2} \gamma_{0} .
\end{gathered}
$$

Here we use $\gamma_{0}+\gamma_{1}+\gamma_{2}=1$ to deduce as we did Eq. 16,

$$
\begin{aligned}
& \gamma_{0}=\frac{1}{1+\sum_{i=2}^{3} k_{i} \cdots k_{2}\left[\mathrm{H}^{+}\right]^{1-i}}=\frac{1}{1+k_{2}\left[\mathrm{H}^{+}\right]^{-1}+k_{2} k_{3}\left[\mathrm{H}^{+}\right]^{-2}} \\
& =\frac{1}{1+10^{-6.3}\left[\mathrm{H}^{+}\right]^{-1}+10^{-16.6}\left[\mathrm{H}^{+}\right]^{-2}}
\end{aligned}
$$

In the range $5.8-8.6$ of $\mathrm{pH}$ which is a regulation by law, both exist in notable quantity. E.g. For $\mathrm{pH}=7$, the rate $\mathrm{CO}_{3}{ }^{2-}$ is

$$
\gamma_{2}=\frac{10^{-2.6}}{1+10^{0.7}+10^{-2.6}}=\frac{1}{1+10^{3.3}+10^{2.6}} \approx 4.110^{-4},
$$

which is neglected in [9]. On p.v. of that paper, $10^{-5} \sim 10^{-2}$ is regarded as negligible quantity.

\section{Conclusion}

As discussed, the main motive of this paper was to explore adaption principle i.e. replacing arsenate occurrences by other Ions like carbonate and phosphates. The main aim of developing this technique is to clean the water being supplied by removing poisonous arsenic occurrences and to use minimum amount of energy. The paper explores the use of oyster shells which are an industrial waste or the removal of arsenic. The analysis has shown that we can save on energy if we keep an optimum $\mathrm{pH}$ and replace the arsenate ions by phosphates or carbonates.

\section{References}

[1] M. Ando, Arsenic contaminate of ground water in India and Bangladesh and its health effect, J. Nat. Inst. Public Health 49 (3) (2000), 266-274.

[2] L. R. Brunson and D. A. Sabatini, Fluoride removal technology for emerging regions, Environ. Engrg Sci. 26 (12) (2009), $1777-1784$.

[3] S. Chen, R.S. Dzeng, M. Yang, K. Chlu, G. Shlen,and M. C. Wal, Arsenic species in ground waters of the black foot disease area Taiwan, Taiwan. Environ. Sci. Tech. 28 (1994), 877-881.

[4] R. Garai, A. K. Chakraborty, S. B. Dey et al., Chronic arsenic poisoning from tube-well water, J. Indian Med. Assoc. 82 (1984), 34-35. 
[5] S. GoldBerg and R. A. Glanbig, Anion sorption on a calcareous, montmorillonitic soil-arsenic, Soil Sci. Am. J. 52 (1988), 1297-1300.

[6] H. Kondo, Basic study on the removal of harmful metalic objects including arsenate from polluted underground water, Doctoral thesis, Kyushu Univ. 1969.

[7] H. Kondo, An outline of arsenic pollution of ground waters in the southern area of Fukuoka Prefecture, Japan Soc. Water Environ. 20 (7) (1997), 438-442.

[8] D. H. Moon, K, W. Kim and I. H. Yoon et al, Stabilization of arsenic-contaminated mine tailings using natural and calcined oyster shells, Environ. Earth Sci. 64 (9) (2011), 597-605.
[9] H. Nishioka, T. Uchida, K. Uchida, T. Yazawa and T. Amako, Optimization of conditions for heat treatment of oyster shells which improves the adsorption rate of ions that give load on environment, J. Soc. Industr. Wastes, Resources Recycling, 22 (2011), 276-283.

[10] T. Tsunematsu, E. Uematsu, K. Saito and H. Tamura, Anti-dissolvation of naturally existing arsenate species by addition of gypsum powder and its mechanism, Rep. Agr. Rural Industr. 80 (2012), 141-150. 